\title{
Microarrays - new possibilities for detecting biological factors hazardous for humans and animals, and for use in environmental protection
}

\author{
Tomasz Mirski', Michał Bartoszcze', Agata Bielawska-Drózd', Romuald Gryko', Janusz Kocik², \\ Marcin Niemcewicz ${ }^{1}$, Krzysztof Chomiczewski ${ }^{3}$ \\ ${ }^{1}$ Biological Threat Identification and Countermeasure Centre of the Military Institute of Hygiene and Epidemiology, \\ Puławy, Poland \\ ${ }^{2}$ Military Institute of Hygiene and Epidemiology, Department of Epidemiology, Warsaw, Poland \\ ${ }^{3}$ Faculty of Chemistry and New Technologies, Military Uniwersity of Technology, Warsaw, Poland
}

Mirski T, Bartoszcze M, Bielawska-Drózd A, Gryko R, Kocik J, Niemcewicz M, Chomiczewski K. Microarrays - new possibilities for detecting biological factors hazardous for humans and animals, and for use in environmental protection. Ann Agric Environ Med. 2016; 23(1): 30-36. doi: $10.5604 / 12321966.1196849$

\begin{abstract}
Both the known biological agents that cause infectious diseases, as well as modified (ABF-Advanced Biological Factors) or new, emerging agents pose a significant diagnostic problem using previously applied methods, both classical, as well as based on molecular biology methods. The latter, such as PCR and real-time PCR, have significant limitations, both quantitative (low capacity), and qualitative (limited number of targets). The article discusses the results of studies on using the microarray method for the identification of viruses (e.g. Orthopoxvirus group, noroviruses, influenza A and B viruses, rhino- and enteroviruses responsible for the FRI (Febrile Respiratory Illness), European bunyaviruses, and SARS-causing viruses), and bacteria (Mycobacterium spp., Yersinia spp., Campylobacter spp., Streptococcus pneumoniae, Salmonella typhi, Salmonella enterica, Staphylococcus aureus, Neisseria meningitidis, Clostridium difficile, Helicobacter pylori), including multiple antibiotic-resistant strains. The method allows for the serotyping and genotyping of bacteria, and is useful in the diagnosis of genetically modified agents. It allows the testing of thousands of genes in one experiment. In addition to diagnosis, it is applicable for gene expression studies, analysis of the function of genes, microorganisms virulence, and allows the detection of even single mutations. The possibility of its operational application in epidemiological surveillance, and in the detection of disease outbreak agents is demonstrated.
\end{abstract}

- Key words

microarrays, detection, viruses, bacteria, health and environmental protection

\section{INTRODUCTION}

Rapid detection and identification of microbial hazards and potential biological warfare agents is usually difficult and time-consuming, especially when traditional microbiological methods are used. Modern molecular biology techniques, based on reverse transcription and/or polymerase chain reaction (RT-PCR / PCR) is a rapid and efficient alternative to traditional methods, but they are usually designed and optimized to detect only a limited number of targets and are rarely used to differentiate various targets [1]. Therefore, it became necessary to search for new diagnostic tools that would be useful for the simultaneous detection of a wide range of different biological agents. Microarrays are the most attractive method in this respect.

The aim of the study was to review the literature concerning the use of microarrays for the identification of bacteria and viruses, as well as showing other advantages of the method, such as the possibilities of its operational use in outbreak detection and its monitoring.

Address for correspondence: Tomasz Mirski, Biological Threat Identification and Countermeasure Centre of the Military Institute of Hygiene and Epidemiology, Puławy, Poland

e-mail: tomaszmirski@wihe.pulawy.pl

Received: 16 December 2013; accepted: 06 May 2014
Microarrays represent technology designed to perform complex, parallel tests based on ligand-binding, such as oligonucleotides, which are placed on a solid support, such as a slide, at high level of packing (density) in order to identify a complex mixture of target sequences. For biological applications the ligands on the array may be DNA, RNA, proteins, polysaccharides, lipids, small organic compounds, or even whole cells $[2,3]$. Among the various possible types of ligands, the most popular and the best known are DNA microarrays $[4,5]$. DNA microarray technology is contributing to a fundamental change in the view of molecular biologists of genes, and is one of the technologies leading to a postgenomic era, which is structural and functional genome analysis $[6,7]$.

In comparison to one of the first DNA microarrays used for the study of 64 Arabidopsis gene expression [8], current microarray technology has come a long way in terms of the number of ligands available on the array, and the range of potential applications. The most famous example of the use of a DNA microarray is messenger RNA level profiling [7], the detection of DNA-protein interactions (e.g. transcription factor binding sites), the determining of the epigenetic status of the genome (such as methylation patterns), changes in DNA copy number, and sequence polymorphisms. The possibility of the parallel testing of a large number of genes 
is a result of the versatility and flexibility in the array design. Currently, there are multiple microarray platforms, and the array design process is easier and more economical. As the microarrays are designed to illustrate a part of, or the whole genome, they provide the opportunity to understand evolution at a molecular level, and genome evolution. The development of the use of microarrays for mapping and quantitative analysis may also contribute significantly to advancing eco-genetic studies [7].

Application of microarrays to detect viruses. The Orthopoxvirus group (OPV) belongs to the Poxviridae family which consists of over 70 members, representing a family of viruses with large genomic DNA containing approximately 200,000 bp [9], which encodes about 200 proteins. Within the OPV types, only four of them can infect humans, mainly through the respiratory epithelium and the skin. The Variola virus, the etiologic agent of smallpox, is representative of the OPV type, and was a serious health problem in the past [10]. Smallpox is a highly infectious disease with a bioterrorism potential, with a mortality rate of up to over $40 \%$ in unvaccinated populations [11]. It is estimated that the disease has caused the death of more people than all others in the history of mankind [12]. Smallpox is the first and only viral disease in history that has been completely eradicated on a global scale. In 1979, the World Health Organization (WHO) confirmed the eradication of smallpox at the end of a successful global vaccination campaign [13]. At present, a serious threat may be the possibility of the use of the variola virus as an agent in a bioterrorist attack [10]. According to Alibek [14], at the beginning of 1980 the Soviet Union began a successful programme of smallpox virus production in large quantities (tons per year) and adapted it for use as a biological weapon in bombs and intercontinental ballistic missiles. According to this source, Russia can also develop a programme of research on finding methods to produce more virulent and infectious recombinant microbe strains [14].

In order to develop an array for the identification of vaccinia virus, 14 complete genomes of viruses available in the databases belonging to the two main families: Chordopoxvirus and Alphaherpesvirus have been used; each comprised subfamilies that grouped pathogens. The pathogens in each group were closely related, demonstrating a high degree of sequence similarity. A multiplex pathogen identification test usually relies on the detection of 'diagnostic regions' derived from common genes or sequences. The diagnostic region consists of a sequence of high homology at its ends, which enables the use of common primers for PCR amplification of these regions for all related pathogens in particular subgroups. The centre fragment contains specific diagnostic databases, which are used to identify each specific pathogen. In order to design an array based on these diagnostic markers computational tools (e.g. MUGDIR software) have been developed that allow coloured visualization of common areas, thereby facilitating the rapid and reliable screening of potential diagnostic regions, allowing further selection of the most useful of them. After group amplification, the PCR products of groupspecific pathogens were identified in the DNA microarray platform in the APEX reaction (Arrayed Primer Extension) [13]. The results of these studies led to the creation of the list of diagnostic regions that may be used as the fingerprinting sequences of each pathogen [15]. The read sequence was then compared to the reference sequence for each pathogen on the array. The comparison result corresponded to the percentage of real signals from the probes for each pathogen. The described designing process of this type of array was preceded by bioinformatics analyzes of the pool of potential diagnostic regions, wherein, in the designing of primers, the following parameters were accounted for: Tm $55-60^{\circ} \mathrm{C}, \mathrm{GC}$ content of $25-75 \%$, the degenerate level should be up to 4 (i.e. up to 2 different bases for each primer), and the length of the amplified region should not exceed $1 \mathrm{~kb}$. In addition, the primers should have maximum versatility within the group. The next step was to evaluate SNP (single nucleotide polymorphism) specific for the pathogen in the acceptance of only the regions containing at least 10 SNPs/ pathogen. At the array integration stage a minimum combination of regions based on the 2 markers for one factor was used, wherein the whole was covered by approximately 50 probes. For the designing and evaluation of probes, PROBES software was used so that the various sequences of the diagnostic region were compared, and all unique diagnostic bases were automatically located. Afterwards, probes used to identify these bases in the APEX reaction were designed. The result of these analysis was to develop a list of APEX probes with expected probes also for other species.

The developed protocol was used for 14 viral pathogens, giving an array for 9 diagnostic regions to detect all of the 14 potential pathogens, wherein each of them was detected by at least 2 markers coated with approximately 50 probes. In addition to species-specific probes, a set of universal probes for Orthopoxvirus group was also introduced on the array in order to eliminate the risk of the emergence of unknown / new OPV species, and to confirm positive results for each OPV member. A prototype array to detect OPV species, named ChiPox [13], which allowed precise identification of all 5 tested agents, was developed. The sensitivity of ChiPox was approximately $100 \mathrm{pfu} / \mathrm{ml}$. The versatility of ChiPox was confirmed during the detection of 5 vaccinia virus strains. The high specificity of the test, using samples of closely related species of viruses was demonstrated, and no false positive results (using human, monkey and mice DNA) were observed.

ChiPox was also evaluated for its suitability for testing clinical samples. For this purpose, rabbits were intra-nasally infected with $10^{3} \mathrm{pfu} /$ animal of vaccinia virus, and after 3-5 days blood samples were tested on ChiPox. All the vaccinia strains were detected, whereas, in the case of all other OPV species, the results were negative. The test allows to distinguish between rabbit pox strains and vaccinia strains. The detection limit of the virus on the ChiPox platform in blood samples was 50-100 pfu/ml, and was consistent with results obtained by real-time PCR. Samples taken from the animals' throats for 3-5 days after infection, tested on ChiPox, detected the presence of virus at a concentration of about $150 \mathrm{pfu} / \mathrm{ml}$. Other authors [16] also used microarrays to detect pox virus, or its variant MVA (Modified vaccinia virus Ankara) obtaining similar, good results.

The microarray technique has been used to study noroviruses and astroviruses [17] that cause gastroenteritis in humans. The microarray method allowed the simultaneous identification of different genogroups and types of these viruses. In order to verify the sensitivity of the method, monoplex-and multiplex-RT-PCR assays at the stage of pre-amplification were used. To determine the sensitivity, precision and accuracy of microarray, 202 stool specimens 
infected with 13 genotypes of noroviruses GI and GII were used. All genotypes except one were detected. In the panel of 74 stool samples, 45 were positive for noroviruses, while conventional PCR detected only 35. Furthermore, microarrays allowed for the detection of a number of double infections with both the above virus types. In the panel of archival samples, astroviruses genotype 4 were detected in Finland from 1977 to 1997.

The usefulness of the microarrays for simultaneous monitoring of several other viruses and their subtypes has been demonstrated and have become a convenient tool for the detection of RNA viruses, for which frequent changes of the panel of primers in the PCR method are required due to the detection of several targets simultaneously [17].

Townsend et al. [18] investigated the usefulness of microarrays in the surveillance of influenza virus infections. Enhanced surveillance requires rapid, reliable and inexpensive analytical techniques providing a detailed analysis of the currently occurring influenza virus strains. The FluChip-55 microarray, designed for relatively rapid identification of influenza A virus subtype $\mathrm{H} 1 \mathrm{~N} 1, \mathrm{H} 3 \mathrm{~N} 2$ and $\mathrm{H} 5 \mathrm{~N} 1$ has been described, in which a narrow set of sequences was chosen to demonstrate the broad spectrum of influenza viruses A and B currently circulating in the human population, including the $\mathrm{A} / \mathrm{H} 5 \mathrm{N1}$ virus, which became an enzootic virus in poultry in south - east Asia and also in Europe [18]. In the blank test of 72 isolates of the influenza virus A and B, RNA was isolated, amplified, hybridized, labelled with a fluorophore and analyzed. The total analysis time was less than 12 hours. The results of the 2 tests showed the presence of specific types and subtypes in $72 \%$ of isolates. False-negative signals were reported for $4 \%$ of the isolates, and false-positive results for $1 \%$. In the great majority of cases in which the presence of incomplete subtypes was observed, the failure was caused by the nucleic acid amplification step, not because of any limits on the same microarray. Similar studies were performed by Kostina et al. [19]. Other authors [20] used a high-density resequencing microarray (RPM) for the detection of avian influenza virus, yielding satisfactory results.

Resequencing Pathogen Microarray (RPM) was used by Wang et al. [21] for typing human rhinoviruses and enteroviruses, causing febrile respiratory illness (FRI), with a significant impact on public health and the global economy. RPM technology gives the possibility of simultaneous differential diagnosis of several pathogens, which is associated with the designing of suitable probes. These authors determined the minimum number of probe sequences (26 for HRV virus, and 13 for HEV virus) that were potentially useful for the detection of all serotypes of those viruses placed on the microarray (RPM-Flu v. 30/31). The specificity of the designed probes was validated using $34 \mathrm{HRV}$ strains and $28 \mathrm{HEV}$ strains. All strains were successfully detected and identified at least to species level. 33 HRV strains and $16 \mathrm{HEV}$ strains were differentiated to serotype. These studies indicated the possibility of the simultaneous detection and differential identification of genetically diverse RNA viruses with a minimum number of prototype sequences, and indicated that the newly-designed RPM-Flu v.30/31 microarray may provide a versatile and specific analysis of HRV and HEV samples. It is presumed that this strategy may also be used for the genetic diversification of other viruses pathogenic for the respiratory tract [22]. Other authors [23] developed microarray probes for the identification and detection of viruses causing SARS (severe acute respiratory syndrome) at the gene level. Hasib et al. [24] developed a flow microarray based on multiplex amplification using ligation-dependent probes involving reverse transcriptase for the detection of European bunyaviruses.

Application of microarrays for detection and identification of bacterial factors. Microarray experiments can be divided into those in which the genomic DNA is used for hybridization, and the study of gene expression using RNA-derived cDNA. Due to the simpler analysis, the former developed rapidly, as exemplified by the use of the array for Mycobacteria, Campylobacter, and Yersinia species. One example is a microarray based on the plasmid partially overlapping the complete genome of Campylobacter jejuni, demonstrating the enormous genetic diversity of clinical strains, with the presence of at least $21 \%$ of alternative genes, which were mostly related to the biosynthesis of surface structures such as flagella, lipooligosaccharides, and capsule, as well as iron assimilation, DNA restriction and sialylation [6]. The arrays, even though they are attractive as a research tool, cannot be used for a comprehensive study of the whole genome of all the new strains since they contain components (printed DNA) of selected sequenced reference strains [6]. The construction of genus- and species-specific arrays representative for all sequenced genes of different strains or species on one plate may somewhat avoid these limitations [6]. Thus, the most important challenge in terms of bacterial genomes is the knowledge of additional genes by sequencing different hybridization products of reference and tested strains, and then printing them on a microarray plate.

Currently, the whole genome microarrays for Campylobacter jejuni, Mycobacterium tuberculosis [25, 26], Francisella tularensis [27], Leptospira interrogans [28], and Yersinia pestis [29] have already been produced, as well as arrays for 500 selected genes of Streptococcus pneumoniae, and the plasmid genes of Salmonella enterica [30], and Yersinia pestis [31]. Each of the arrays can be modified depending on the specific user requirements.

The whole genome arrays for Streptococcus pneumoniae, Staphylococcus aureus, and Neisseria meningitidis are currently in the development, design or manufacture stages. The production of microarrays for Bordetella pertussis, Clostridium difficile, Chlamydia spp., Helicobacter pylori, Listeria monocytogenes, and Mycobacterium spp. [32] is also expected.

Access to genetic databases, and more complete bacterial genome sequences, are synchronized with the development of a number of technologies for the study of gene function. With regard to the pathogenesis of bacterial diseases, one of the main approaches aims at the definition of a set of genes determining bacterial virulence and the identification of various aspects of the regulation of these genes and their expression on mRNA and protein levels. Bacterial virulence may be determined as the appropriate, temporal and spatial expression of the overlapping groups of genes necessary for a specific phase of infection, in response to specific environmental signals with which the host organism has contact [6].

Different strains of the same species may vary considerably (Fitzgerald et al. showed more than $20 \%$ of the variability in the Staphylococcus aureus genome) [33], but the complete sequence is available only for a few reference strains. By 
comparing templates with probes derived from the sequenced reference strains, microarrays provide a unique tool for the screening of the sequence of any number of strains without the necessity of sequencing [34]. In 2001, a high density oligonucleotide microarray was implemented to detect small deletions in the genome of Mycobacterium tuberculosis clinical strains, the deletion pattern and the number correlated respectively with the clonality, and the probability of forming cavities, thus providing significant usefulness in epidemiological studies [35]. The versatility of the microarrays was used in inter-species studies of large plasmids in Salmonella enterica and Escherichia coli [36]. The constructed array was based on the 500-800 bp of plasmids fragments, which allowed the evaluation of diversity, as well as some of the evolutionary aspects of these plasmids and their transfer between species. Bae et al. [37] designed probes specific for the unsequenced genes of Salmonella strains. They isolated the specific sequences by suppressive subtractive hybridization against sequenced reference strains. These probes were then used to obtain subspeciesspecific microarrays. In recent studies, 7 previously described complete sequences of Staphylococcus aureus have been used to develop a complete multi-genomic array capable of sensitive discrimination of related isolates [38]. The result was an answer to the question of how isolates of the same epidemic clone of methicillin-resistant Staphylococcus aureus differ significantly in terms of the transfer of mobile genetic elements, including virulence and antibiotic resistance genes.

Most studies on microarrays are focused on a limited set of genes. A common use of DNA microarrays in clinical microbiology is detecting the presence and association of selected genes involved in the pathogenesis of infection with resistance to antimicrobial agents, as well as other genes or their groups directly related to the disease [34]. The detection arrays are cheaper because of the lower number of probes required, and may be very useful in studies of specific aspects of microbial genetics. A common method of assessing unknown gene patterns among known isolates is typing; identification of species is based on the detection of a set of known genes in unknown isolates. DNA microarrays are more useful in a large number of probes. At first, the oligonucleotide array for screening for the presence of selected species-specific sequences of 6 Listeria genes was developed, allowing a clear distinction of 6 different species [34]. In other studies, 18 different microorganisms selected from potential biological warfare agents were subjected to identification and typing by the hybridizing of the fragments of approximately 100 bases derived from genomic DNA or retroviral RNA with 50,000 oligonucleotide probes [34]. With a large number of probes it was possible to detect more species-specific sequences. The studies on the sensitivity of microarrays developed for a wide range of bacterial biological warfare agents belonging to the A class (Bacillus anthracis, Francisella tularensis, and Yersinia) showed the ability to detect the amplified DNA from 50 bacteria/ml of blood [34]. In other studies, specific amplified 23s sequences derived from Pseudomonas aeruginosa and Acinetobacter baumannii cultured from clinical samples were identified [34]. Comparable or even better sensitivity compared to microscopy and culture was shown, with $100 \%$ specificity. Similarly, Lehner et al. [39] validated an oligonucleotide array designed for the specific identification of enterococci species. In the studies carried out in order to distinguish Chlamydiae at species level, the most variable part of the conserved ribosomal operon sequence was selected to detect single mutations [34]. These authors performed the hybridization of control isolates in a high-density photolitographic array, selected the most suitable probes, and used them to construct a cheaper lower-density spotted array. In recent studies, a microarray with 19-mer probes binding variable regions on the 5 'end of the 16S RNA genes of several of the most common blood isolates was developed [34]. Marlowe et al. [40] were also able to identify single and multiple isolates from a large number of blood cultures with $100 \%$ sensitivity and $96 \%$ specificity using specific rRNA probes.

Balmer et al. [41] used an oligonucleotide microarray for the rapid serotyping of Escherichia coli DNA. As a targeting sequence for the $\mathrm{O}$-antigen they selected genes encoding flippase $(w z x)$, and polymerase $(w z y)$, while the $f l i C$ gene and related genes encoding flagellar monomer were selected as representative for the $\mathrm{H}$ phenotype. Based on a detailed bioinformatics analysis, and designing of oligonucleotides, an array-tube assay was developed in which a rapid method of DNA isolation was coupled with a multiple, specific, linear labelling procedure, and hybridization analysis of biotinylated amplicons. The microarray contained doubled oligonucleotide DNA probes representing the 24 most epidemiologically important from more than 180 known $\mathrm{O}$-antigens, as well as 47 of the 53 different $\mathrm{H}$-antigens. Evaluation of the microarray with a printed set of particular strains representing all $\mathrm{O}$ - and $\mathrm{H}$-serotypes indicated their high sensitivity and specificity. All of the 24 conventionally typed $\mathrm{O}$-groups, and all of the $47 \mathrm{H}$-serotypes were correctly identified in these studies. The non-typeable strains with the previous serotyping assays yielded clear results in a new array-tube assay, which provided a valuable alternative to classical serotyping.

The oligonucleotide microarray was also used by Bavykin et al. [42] for the analysis of 16S- and 23S-rRNA to distinguish Bacillus anthracis and closely related microorganisms. This was the first microarray for identifying Bacillus anthracis, and distinguishing within seven subgroups (Anthracis, Cereus A and B, Thuringiensis A and B, and Mycoides A and $B$ ) in pure cell cultures, and environmental samples using rRNA sequence. The microarray contained complete 'match / mismatch' probe pairs sufficiently specific to distinguish single nucleotide polymorphism (SNPs), and for the detection of target organisms within $5 \mathrm{~min}$. The usefulness of the microarray to determine subgroup membership to the Bacillus cereus group isolates without rRNA sequencing was also demonstrated. The correlation of these 7 subgroups with grouping based on MLST (multilocus sequence typing), AFLP (fluorescent amplified fragment length polymorphism analysis) and MME (multilocus enzyme electrophoresis) of a wide variety of different genes was observed. The specific differences for particular subgroups in toxin profiles, psychrotolerance, and the presence of certain plasmids were also shown, which suggests that the existence of 7 subgroups is not only based on neutral genomic polymorphism, but reflects the differences both in the genotype as well as in the phenotype of organisms of the Bacillus cereus group. Similar studies were also conducted to analyze the transposon insertion sites in Bacillus anthracis in order to identify the genes responsible for sporulation and germination.

In the studies of Frangoulidis et al. [43] the usefulness of a new, rapid, 'low cost and density' (LCD) DNA microarray 
for the detection of Coxiella burnetii was tested. In addition to the commonly used genomic target IS1111, the recently described marker adaA (acute disease antigen A) was used here. It was found that microarray technology allows for rapid (45 minutes with only 15 minutes of manual work), sensitive, specific, and cost-effective detection. Both the pure isolates, as well as animal and human clinical samples, can be successfully analyzed by this method.

Panicker et al. [44] described in their study gene-specific DNA microarrays which, in combination with the multiplex PCR method, was used for the universal detection of pathogenic Vibrio naturally found in warm coastal waters and shellfish. In these microarrays, the oligonucleotide probes for $v v h$ and $v i u B$ genes of Vibrio vulnificus; ompU, toxR, tcpI and $h I y A$ genes of $V$. cholerae, and $t h, t d h$, trh genes, and open reading frames of $V$. parahaemolyticus were deposited on epoxysilane, 12-well teflon slides (using a MicroGrid II). The detection sensitivity for pure non-enriched cultures was $10^{2}-10^{3} \mathrm{CFU} / \mathrm{ml}$, with $100 \%$ specificity. 5 hours enrichment of the sample allowed the detection of $1 \mathrm{CFU}$ in $1 \mathrm{~g}$ of oyster tissue homogenate. The use of DNA microarrays to study oysters showed the presence in them of Vibrio vulnificus, and Vibrio parahaemolyticus.

Straub et al. [45] applied oligonucleotide microarrays in the specific detection of Cryptosporidium spp. and to differentiate between closely related isolates of Cryptosporidium parvum and Cryptosporidium species, and to differentiate between the primary genotypes infectious for humans. In order to investigate the specificity of the method, 2 isolates of Cryptosporidium parvum genotype I (TU502 and UG502), 2 isolates of Cryptosporidium parvum genotype II (Iowa and GCH1), and DNAs originating from 22 organisms other than Cryptosporidium, were used. Only DNAs of Cryptosporidium parvum isolates gave labelled amplicons, which might be hybridized and detected on the array. The hybridization patterns were significantly different between genotypes, but the identification of SNPs required statistical analysis of data concerning the signal intensity. The results indicate that an appropriate mismatch distinction can be detected for all 7 SNPs of the UG502 isolate, 5 of the 7 SNPs for the TU502 isolate, and 6 of the 7 SNPs for both the Iowa, and $\mathrm{GCH} 1$ isolates. The microarray method clearly differentiated isolates of I and II genotypes, and showed the potential to differentiate between other isolates and species on a single microarray. The method can be a powerful new tool in the assessment of point and non-point sources of pollution in natural water resources.

Davignon et al. [46] in their study evaluated the utility of oligonucleotide resequencing microarrays to identify Group A streptococci (GAS), and their antibiotic resistance markers. They developed an assay platform which relied on the use of DNA resequencing microarrays with a random nucleic acid amplification or multiplex PCR. This method showed excellent compatibility of detection of Streptococcus pyogenes in clinical samples with the conventional culture method.

Lian et al. [47] developed a sensitive microarray system based on antibodies (Ab) for the specific detection of bioterrorism agents, for example ricin, cholera toxin (CT), and staphylococcal enterotoxin B (SEB). The detection system has been successfully used to detect toxins in milk, apple juice, and blood samples. These authors were able to detect ricin in a concentration of $100 \mathrm{pg} / \mathrm{ml}$ in buffer, and $1 \mathrm{ng} /$ $\mathrm{ml}$ in the infected apple juice or milk, while the CT and SEB were detected in a concentration of $10 \mathrm{pg} / \mathrm{ml}$ in buffer, and $100 \mathrm{pg} / \mathrm{ml}$ in the infected apple juice or milk. The high specificity of the detection of toxin mixtures in the samples with a similar sensitivity has also been shown. The matrix effects of blood samples on the detection of toxin mixtures seem to be smallest at a concentration of toxins greater or equal to $100 \mathrm{ng} / \mathrm{ml}$.

DNA microarrays can be used in screening for the presence of a larger number of antimicrobial factor resistance genes, compared to other molecular methods [34]. In a basic approach, they are used to obtain more interesting, and sometimes unexpected, information on the response of bacteria to drugs. In one of these studies, Pseudomonas aeruginosa showed a uniform activation of pyocins chromosomal region (approximately 35 open reading frames) in the treatment of ciprofloxacin [34]. In recent studies, a gene expression profile database of Bacillus subtilis exposed to 14 different antibiotics, as well as antibiotic-susceptible mutants, was obtained [34]. From an epidemiological point of view, DNA microarrays offer the possibility of comprehensive and final screening of a large number of isolates from the collection in order to obtain data on the prevalence and spread of resistance determinants in time and geographical areas. Rasooly et al. [34] used a technique based on the multiplex PCR method for the identification of 6 erythromycin resistance genes in Staphylococcus aureus. The oligonucleotide microarrays of a wide range of species for the complex detection of 65 genes conferring resistance to macrolide antibiotics has also been developed [34]. Another group of researchers was able to identify 90 amplified antibiotic resistance genes commonly found in gram-positive bacteria using the 30-mer oligonucleotide microarray with 2 different probes for each gene. In this case, the authors were also able to neglect the PCR amplification of the template. In several cases of non-compliance between phenotypic resistance and the microarray results, the authors indicated the possibility of mutations or deletions which might be detected only by special microarrays containing more probes of shorter length, binding the whole gene. In other studies highlighting the relationship between a large number of specific probes and methods of labeling without amplification, 61 antibiotic resistance genes in 51 different species were detected. More focused oligonucleotide microarrays for the detection of resistance caused by single nucleotide mutations have also been developed. An important application is the detection of extended spectrum beta-lactamases (ESBL) or inhibitor resistance phenotype [34]. Another group of researchers selected the $r p o B$ gene sequence of Mycobacterium tuberculosis for detecting single nucleotide mutations causing resistance to rifampicin in the amplified part of this gene [34]. Yu et al. [34] were able to properly detect mutations in the amplified DNA gyrase gene in Escherichia coli, determining quinolone antibiotic resistance. Although they selected only 2 of the mutation sites, more than 50 19-mer probes have been designed to focus on all possible hidden, and resistance-causing mutations.

Anderson et al. [48] applied DNA microarrays to study the genetic mechanisms of the immune response to the infection of murine macrophages by Francisella tularensis. These microarrays represent approximately 18,500 genes (20,600 clones). The adaptive response at the time was weak, wherein at most 81 clones were differently regulated after 
infection and $240 \mathrm{~min}$. later. For all 5 time points, 229 clones met the criteria of different regulation, i.e. the ratio between infected and uninfected cells was at least 1:7. It has been found that many of the differently regulated genes are able to react to stress, particularly oxidative stress. The activation of genes responsible for depletion in glutathione, which is probably a result of the activity of mechanisms induced by Francisella tularensis, has been also observed. Overall, a clear loss of the capacity of the organism for the immune inflammatory response was found. Yang et al. [49] used microarrays to identify potential vaccines against Leptospira interrogans. For this purpose, a DNA microarray for Leptospira interrogans strain \#56601 for CGH (comparative genomic hybridization) analysis, and in vitro analysis of the transcriptome was constructed. 3,007 different genes in pathogenic serovars, in which 1,427 genes had high transcription levels, were identified using CGH. The presence of 565 transitional genes between genes encoding the surface proteins and 307 other genes was found.

The use of microarrays for the detection and identification of fungal pathogens [50], as well as in studies of psychrophilic soil bacteria's response to hydrocarbon pollution and bioremediation treatments, is also important [51].

Applications of microarrays in epidemic outbreaks. In addition to the above-mentioned applications, DNA microarrays have been successfully tested in Epidemic Outbreak Surveillance (EOS). Microarray technology was used to carry out operational (field) tests of up to 300 samples per day. The designed DNA microarrays were able to detect 20 natural (including avian flu), and bioterrorist agents, and their differentiation into specific strains. The exercises showed the full suitability of the system for EOS, and the protection of mass events against biological threats. Further development of microarray technology will allow their use even at the PC (point of care) level. In epidemiological recognition showing the presence of unknown biological agents, or those undergoing profound genetic modification in samples by using the microarray technique, will be extremely valuable [52]. This ability has particular importance in countering the dramatic risks posed by biotechnology in terms of creating Advanced Biological Weapons (ABW).

\section{CONCLUSIONS}

Based on the presented review of the studies on the possibilities of using the microarray method in the diagnosis of biological agents, it can be found that it has huge diagnostic potential which can be used not only for the identification of known microorganisms, but also for modified new and newly-emerging microorganisms. The microarray method is specific, sensitive and cost-effective. Due to the ability to test thousands of genes in a single experiment, the microarray method is superior to other diagnostic methods, and even allows the obtaining of information on the single mutations level.

\section{REFERNCES}

1. Leski TA, Lin B, Malanoski AP, Wang Z, Long NC, Meador CE, et al. Testing and validation of high density resequencing microarray for broad range biothreat agents detection. PLoS One. 2009; 4(8): 1-8.

2. Gaseitsiwe S, Valentini D, Mahdavifar S, Reilly M, Ehrnst A, Maeurer M. Peptide microarray-based identification of Mycobacterium tuberculosis epitope binding to HLA-DRB1 ${ }^{\star} 0101, \mathrm{DRB}^{\star} 1501$, and $\mathrm{DRB} 1^{\star} 0401$. Clin Vaccine Immunol. 2010; 17(1): 168-175.

3. Ziauddin J, Sabatini DM. Microarrays of cells expressing defined cDNAs. Nature. 2001; 411(6833): 107-110.

4. Karczmarczyk M, Bartoszcze M. DNA microarrays - new tool in the identification of biological agents. Przegl Epidemiol. 2006; 60: 803-811.

5. Palka-Santini M, Cleven BE, Eichinger L, Krönke M, Krut O. Large scale multiplex PCR improves pathogen detection by DNA microarrays. BMC Microbiol. 2009; 9: 1

6. Butcher PD. The 1st Symposium of the Wellcome Trust-Funded MultiCollaborative Microbial Pathogen Microarray Facility-BmuG@S 2002: 'Bacterial Pathogens, Microarrays and Functional Genomics'. Comp Funct Genomics. 2002; 3(4): 326-329.

7. Shiu SH, Borevitz JO. The next generation of microarray research: applications in evolutionary and ecological genomics. Heredity (Edinb). 2008; 100(2): 141-149.

8. Schena M, Shalon D, Davis RW, Brown PO. Quantitative monitoring of gene expression patterns with a complementary DNA microarray. Science. 1995; 270(5235): 467-470.

9. Massung RF, Liu LI, Qi J, Knight JC, Yuran TE, Kerlavage AR, et al. Analysis of the complete genome of smallpox variola major virus strain Bangladesh-1975. Virology. 1994; 201(2): 215-240.

10. Henderson DA, Inglesby TV, Bartlett JG, Ascher MS, Eitzen E, Jahrling $\mathrm{PB}$, et al. Smallpox as a biological weapon: medical and public health management. Working Group on Civilian Biodefense. JAMA. 1999; 281(22): 2127-2137.

11. Henderson DA. Countering the posteradication threat of smallpox and polio. Clin Infect Dis. 2002; 34(1): 79-83.

12. Moss B. Genetically engineered poxviruses for recombinant gene expression, vaccination, and safety. Proc Natl Acad Sci U S A. 1996; 93(21): 11341-11348.

13. Beth-Din A, Israeli O, Shifman O, Stein D, Ben-Arie E, Paran N, et al. Genetic detection of vesicle forming pathogens by Arrayed Primer Extension (APEX). In: Shafferman A. The Challenge of Highly Pathogenic Microorganisms, Springer Science + Business Media B.V. 2010: p.173-182.

14. Alibek K, Handelman S. Biohazard: The chilling true story of the largest covert biological weapons progra $m$ in the world - told from inside by the man who ran it. Random House, 1999.

15. Podder M, Ruan J, Tripp BW, Chu ZE, Tebbutt SJ. Robust SNP genotyping by multiplex PCR and arrayed primer extension. BMC Med Genomics. 2008; 1: 5.

16. Davies DH, Wyatt LS, Newman FK, Earl PL, Chun S, Hernandez JE, et al. Antibody profiling by proteome microarray reveals the immunogenicity of the attenuated smallpox vaccine modified vaccinia virus ankara is comparable to that of Dryvax. J Virol. 2008; 82(2): 652-663.

17. Jääskeläinen AJ, Maunula L. Applicability of microarray technique for the detection of noro- and astroviruses. J Virol Methods. 2006; 136(1-2): 210-216.

18. Townsend MB, Dawson ED, Mehlmann M, Smagala JA, Dankbar DM, Moore CL, et al. Experimental evaluation of the FluChip diagnostic microarray for influenza virus surveillance. J Clin Microbiol. 2006; 44(8): 2863-2871.

19. Kostina EV, Riabinin VA, Agafonov AP, Ternovoi VA, Siniakov AN. Microarray for diagnostics of human pathogenic influenza A viruses subtypes. Bioorg Khim. 2011; 37(5): 715-717.

20. Lin B, Malanoski AP, Wang Z, Blaney KM, Long NC, Meador CE, et al. Universal detection and identification of avian influenza virus by use of resequencing microarrays. J Clin Microbiol. 2009; 47(4): 988-993.

21. Wang Z, Malanoski AP, Lin B, Kidd C, Long NC, Blaney KM, et al. Resequencing microarray probe design for typing genetically diverse viruses: human rhinoviruses and enteroviruses. BMC Genomics. 2008; 9: 577.

22. Lin B, Blaney KM, Malanoski AP, Ligler AG, Schnur JM, Metzgar $\mathrm{D}$, et al. Using a resequencing microarray as a multiple respiratory pathogen detection assay. J Clin Microbiol. 2007; 45(2): 443-452.

23. Chou CC, Lee TT, Chen CH, Hsiao HY, Lin YL, Ho MS, et al. Design of microarray probes for virus identification and detection of emerging viruses at the genus level. BMC Bioinformatics. 2006; 7: 232. 
24. Hasib L, Dilcher M, Hufert F, Meyer-König U, Weidmann M. Development of a flow-through microarray based reverse transcriptase multiplex ligation-dependent probe amplification assay for the detection of European Bunyaviruses. Mol Biotechnol. 2011; 49(2): 176-186.

25. Rodin S, Andersson AF, Wirta V, Eriksson L, Ljungström M, Björkholm $\mathrm{B}$, et al. Performance of a 70-mer oligonucleotide microarray for genotyping of Campylobacter jejuni. BMC Microbiol. 2008; 8: 73.

26. Waddell SJ, Laing K, Senner C, Butcher PD. Microarray analysis of defined Mycobacterium tuberculosis populations using RNA amplification strategies. BMC Genomics. 2008; 9: 94.

27. Broekhuijsen M, Larsson P, Johansson A, Byström M, Eriksson U, Larsson E, et al. Genome-wide DNA microarray analysis of Francisella tularensis strains demonstrates extensive genetic conservation within the species but identifies regions that are unique to the highly virulent F. tularensis subsp. tularensis. J Clin Microbiol. 2003; 41(7): 2924-2931.

28. Lo M, Bulach DM, Powell DR, Haake DA, Matsunaga J, Paustian ML, et al. Effects of temperature on gene expression patterns in Leptospira interrogans serovar Lai as assessed by whole-genome microarrays. Infect Immun. 2006; 74(10): 5848-5859.

29. Zhou D, Han Y, Song Y, Tong Z, Wang J, Guo Z, et al. DNA microarray analysis of genome dynamics in Yersinia pestis: insights into bacterial genome microevolution and niche adaptation. J Bacteriol. 2004; 186(15): 5138-5146.

30. Chan K, Kim CC, Falkow S. Microarray-based detection of Salmonella enterica serovar Typhimurium transposon mutants that cannot survive in macrophages and mice. Infect Immun. 2005; 73(9): 5438-5449.

31. Li B, Jiang L, Song Q, Yang J, Chen Z, Guo Z, et al. Protein microarray for profiling antibody responses to Yersinia pestis live vaccine. Infect Immun. 2005; 73(6): 3734-3739.

32. Hinds J, Laing KG, Mangan JA, Butcher PD. Microarrays for Microbes: the BmuG@S Approach. Comp Funct Genomics. 2002; 3(4): 333-337.

33. Fitzgerald JR, Sturdevant DE, Mackie SM, Gill SR, Musser JM. Evolutionary genomics of Staphylococcus aureus: insights into the origin of methicillin-resistant strains and the toxic shock syndrome epidemic. Proc Natl Acad Sci U S A. 2001; 98(15): 8821-8826.

34. Cassone A, Giordano A, Pozzi G. Bacterial DNA microarrays for clinical microbiology: the early logarithmic phase. Front Biosci. 2007; 12: 2658-2669.

35. Kato-Maeda M, Rhee JT, Gingeras TR, Salamon H, Drenkow J, Smittipat $\mathrm{N}$, et al. Comparing genomes within the species Mycobacterium tuberculosis. Genome Res. 2001; 11(4): 547-554.

36. Call DR, Kang MS, Daniels J, Besser TE. Assessing genetic diversity in plasmids from Escherichia coli and Salmonella enterica using a mixedplasmid microarray. J Appl Microbiol. 2006; 100(1): 15-28.

37. Bae JW, Rhee SK, Nam YD, Park YH. Generation of subspecies levelspecific microbial diagnostic microarrays using genes amplified from subtractive suppression hybridization as microarray probes. Nucleic Acids Res. 2005; 33(13): 113.

38. Witney AA, Marsden GL, Holden MT, Stabler RA, Husain SE, Vass JK, et al. Design, validation, and application of a seven-strain
Staphylococcus aureus PCR product microarray for comparative genomics. Appl Environ Microbiol. 2005; 71(11): 7504-7514.

39. Lehner A, Loy A, Behr T, Gaenge H, Ludwig W, Wagner M, et al. Oligonucleotide microarray for identification of Enterococcus species. FEMS Microbiol Lett. 2005; 246(1): 133-142.

40. Marlowe EM, Hogan JJ, Hindler JF, Andruszkiewicz I, Gordon P, Bruckner DA. Application of an rRNA probe matrix for rapid identification of bacteria and fungi from routine blood cultures. J Clin Microbiol. 2003; 41(11): 5127-5133.

41. Ballmer K, Korczak BM, Kuhnert P, Slickers P, Ehricht R, Hächler H. Fast DNA serotyping of Escherichia coli by use of an oligonucleotide microarray. J Clin Microbiol. 2007; 45(2): 370-379.

42. Bavykin SG, Mikhailovich VM, Zakharyev VM, Lysov YP, Kelly JJ, Alferov OS, et al. Discrimination of Bacillus anthracis and closely related microorganisms by analysis of $16 \mathrm{~S}$ and $23 \mathrm{~S}$ rRNA with oligonucleotide microarray. Chem Biol Interact. 2008; 171(2): 212-235.

43. Frangoulidis D, Rodolakis A, Heiser V, Landt O, Splettstoesser W, Meyer H. DNA microarray-chip based diagnosis of Q-fever (Coxiella burnetii). Clin Microbiol Infect. 2009; 15(2): 165-166.

44. Panicker G, Call DR, Krug MJ, Bej AK. Detection of pathogenic Vibrio spp. in shellfish by using multiplex PCR and DNA microarrays. Appl Environ Microbiol. 2004; 70(12): 7436-7444.

45. Straub TM, Daly DS, Wunshel S, Rochelle PA, DeLeon R, Chandler DP. Genotyping Cryptosporidium parvum with an hsp70 singlenucleotide polymorphism microarray. Appl Environ Microbiol. 2002; 68(4): 1817-1826.

46. Davignon L, Walter EA, Mueller KM, Barrozo CP, Stenger DA, Lin B. Use of resequencing oligonucleotide microarrays for identification of Streptococcus pyogenes and associated antibiotic resistance determinants. J Clin Microbiol. 2005; 43(11): 5690-5695.

47. Lian W, Wu D, Lim DV, Jin S. Sensitive detection of multiplex toxins using antibody microarray. Anal Biochem. 2010; 401(2): 271-279.

48. Andersson H, Hartmanová B, Rydén P, Noppa L, Näslund L, Sjöstedt A. A microarray analysis of the murine macrophage response to infection with Francisella tularensis LVS. J Med Microbiol. 2006; 55(8): 10231033.

49. Yang HL, Zhu YZ, Qin JH, He P, Jiang XC, Zhao GP et al. In silico and microarray-based genomic approaches to identifying potential vaccine candidates against Leptospira interrogans. BMC Genomics. 2006; 7: 293.

50. Spiess B, Seifarth W, Hummel M, Frank O, Fabarius A, Zheng C, et al. DNA microarray-based detection and identification of fungal pathogens in clinical samples from neutropenic patients. J Clin Microbiol. 2007; 45(11): 3743-3753.

51. Yergeau E, Arbour M, Brousseau R, Juck D, Lawrence JR, Masson L, et al. Microarray and real-time PCR analyses of the responses of high-arctic soil bacteria to hydrocarbon pollution and bioremediation treatments. Appl Environ Microbiol. 2009; 75(19): 6258-6267.

52. Uttamchandani M, Neo JL, Ong BN, Moochhala S. Applications of microarrays in pathogen detection and biodefence. Trends Biotechnol. $2009 ; 27(1): 53-61$. 